\title{
USE OF ALLOY 718 AND 725 IN OIL AND GAS INDUSTRY
}

\author{
Rashmi B. Bhavsar, P.E., \\ Schlumberger Reservoir Completions Center, \\ 14910 Airline Road \\ Rosharon, TX 77583, USA
}

\author{
Anthony Collins, Ph.D. \\ Schlumberger Sugarland Product Center \\ 110 Schlumberger Drive. MD4 \\ Sugarland, TX 77478, USA
}

\author{
Seth Silverman \\ Schlumberger Completion Systems \\ 7030 Ardmore Street \\ Houston, TX 77054, USA
}

\begin{abstract}
Schlumberger started using alloy 718 in the early 1980s for downhole equipment. A need for completing high-pressure gas wells required a high strength alloy with good corrosion resistance to gas containing high $\mathrm{CO}_{2}$ and $\mathrm{H}_{2} \mathrm{~S}$ for completion equipment. Alloys like $\mathrm{C}-276$ were available and offered excellent corrosion resistance to anticipated fluids. However, it was available only as high-strength tubing and did not provide wall thickness and uniformity of strength across the wall thickness. The technology for cold-worked, high-strength bar was not developed at that that time. A study for various heat treatments for under- and over-aging was carried out to achieve desirable strength and toughness. The heat treatment and mechanical properties were finalized based on stress corrosion cracking results. The heat treatment and maximum hardness were governed for sour service application. This limited the maximum strength that can be obtained in 718. A welding procedure was developed for artificial gas lift applications.
\end{abstract}

The use of 718 was limited to sour service at moderate temperatures and in the absence of free sulfur. For severe corrosive applications at higher temperatures, alloy 725 with higher Molybdenum was introduced. This alloy provided a better cracking resistance in severe applications based on laboratory testing. Later the heat treatment was modified to offer higher strength. The use of higher strength 725 allows equipment to be manufactured with the maximum ID and minimum OD to increase oil and gas production at a lower completion cost.

718 has also been used in downhole measurement tools, especially in measurement while drilling (MWD). Here, the primary reason is the need for a nonmagnetic alloy with high strength, because magnetic surveying is used to measure the well orientation. At the same time, the material must resist corrosion in drilling mud that may be saturated with salt. Most other nonmagnetic materials available at the same strength level rely on cold work to some extent and are, therefore, not readily available in large diameters.

Finally, 718 has been used directly for drill string components, where it applies a favorable combination of high-fatigue strength and high-corrosion resistance with non-magnetism. In order to maximize fatigue resistance, a modified heat treatment has been developed to produce fine grain size in large diameter forgings.

\footnotetext{
Superalloys 718. 625.706 and Various Derivatives Edited by E.A. Loria

TMS (The Minerals. Metals \& Materials Society), 2001
} 


\section{Introduction}

In the early 1980s, a need developed for a heat-treatable, high-strength corrosion resistant alloy (CRA) for oil and gas production wellhead and completion components. Cold worked nickelchrome CRAs were utilized for tubing in wells that were drilled deeper, hotter and higher in pressure. The higher pressures required higher strength materials due to hole size limitations. Cold worked CRAs were not suitable for machining intricate components. Cold worked CRA tubular goods were made with thinner walls and had a limited wall thickness range.

For completion equipment, low alloy steels and stainless steels are typically used. Monel $® \mathrm{~K}$ 500 was used for premium applications where higher strength and corrosion resistance was required. The targeted deep gas wells were high in $\mathrm{CO}_{2}$ and $\mathrm{H}_{2} \mathrm{~S}$, and had bottom hole temperatures that were in excess of $300^{\circ} \mathrm{F}$. Low alloy steels experienced a high rate of corrosion under these conditions. Stainless steels were not suitable in $\mathrm{H}_{2} \mathrm{~S}$ environments due to their poor resistance to sulfide and chloride stress corrosion cracking. Monel experiences a high rate of corrosion in environments containing $\mathrm{H}_{2} \mathrm{~S}$ and sulfur at these temperatures. High nickel chrome alloys like X-750 experienced field failures and were not considered suitable for the application.

The initial need for a new material to fill this high $\mathrm{H}_{2} \mathrm{~S}$, high-pressure gas well application was driven by oil companies operating in Mississippi and the Gulf of Mexico. They required subsurface safety valves rated to handle 15,000- and 20,000-psi pressures. The tubing specified was 2-7/8-in. and 3-1/2-in. alloy C-276. The valve ODs were 5.25 in. to 5.75 in., and the valve ID was $2.375 \mathrm{in}$. The subsurface safety valves required heavy wall hollows or 5.5 -in. to 6.0 -in. OD round bars. Alloy C-276 alloys were evaluated as heavy wall tubular, but the tubing had a significant gradient in strength from the OD to the ID. There was also marked directionality in mechanical properties due to heavy cold work. See Figure 1.

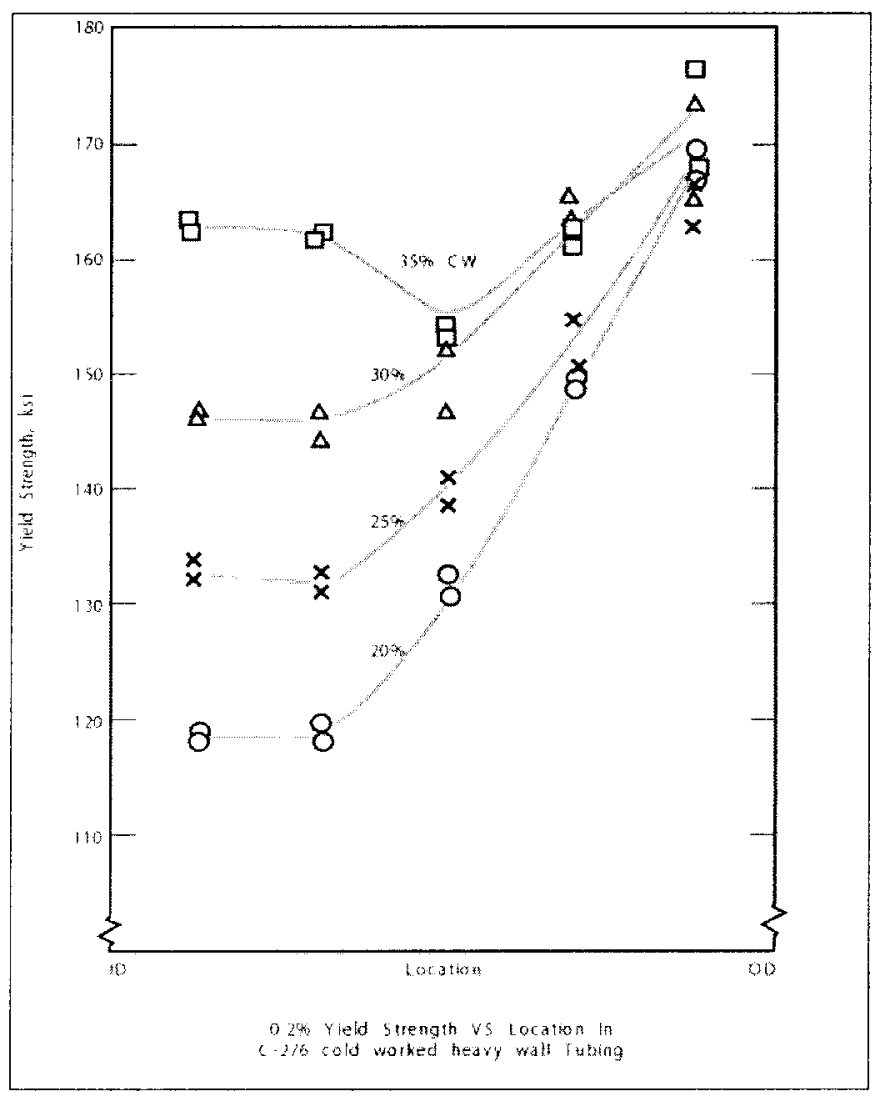

Figure 1: Alloy C-276 variation in mechanical properties across wall thickness 
Alloy 718 was selected due to its high-strength, high-corrosion resistance and availability in various sizes. Its initial use was for subsurface safety valves. Figure 2 shows the typical components of a subsurface safety valve. As one can see, there are several components that are tubing mounted and carry tensile loading of the tubing as well as internal pressure that require heavy wall thickness. These valves are designed to hold 1.5 times the working pressure at room temperature. For a 20 -ksi rating, they have to hold 30-ksi hydraulic pressure. The upper and lower subs of the valve are connected tubing using premium threads and are designed to carry tensile loading of the tubing. Certain components are sealing components that have to seal gas low-pressure as well as high-pressure. Typical service temperatures would vary from a low temperature of less than $100^{\circ} \mathrm{F}$ to a production temperature in excess of $300^{\circ} \mathrm{F}$. Alloy 718 , which was produced at that time, was heat-treated to aerospace requirements in a high strength condition. The high-strength condition was not desirable for maximum stress corrosion cracking resistance. The design requirement for the valve was to have a 120-ksi minimum yield strength material. This required the initiation of a heat treatment evaluation program to determine the optimal microstructure for toughness and corrosion resistance.

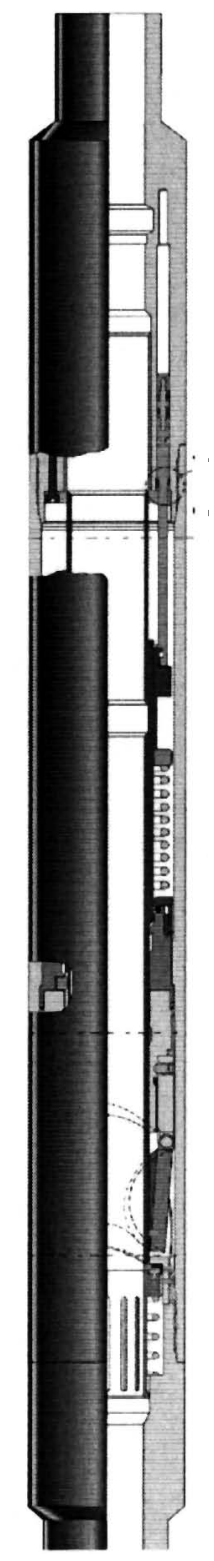

Figure 2: Typical subsurface safety valve assembly 


\section{Melting Requirements}

Double vacuum melted material was specified to keep the residual elements, carbides, nitrides and oxides at low levels. Specifying low levels of these residual elements allowed control of the microstructure and phase morphologies. Specifically, carbon was specified to $.045 \%$ max, and $\mathrm{P}, \mathrm{S}, \mathrm{Pb}, \mathrm{Se}$, and $\mathrm{Bi}$ were specified to ppb levels. $\mathrm{Ti}, \mathrm{Al}$ and $\mathrm{Nb}$ levels were tightly controlled as well. See Table I for oil patch grade 718 typical chemical composition.

Table I Alloy Compositions

\begin{tabular}{lccc}
\hline Element & 718 & 925 & 725 \\
\hline $\mathrm{C}$ & 0.045 & 0.03 & 0.03 \\
$\mathrm{Cr}$ & $17-21$ & $19.5-22.5$ & $19-22.5$ \\
$\mathrm{Ni}$ & $50-55$ & $45-46$ & $55-59$ \\
$\mathrm{Mo}$ & $2.8-3.3$ & $2.5-3.5$ & $7.0-9.5$ \\
$\mathrm{Cu}$ & 0.23 & $1.5-3.5$ & -- \\
$\mathrm{Fe}$ & balance & balance & balance \\
$\mathrm{Mn}$ & 0.35 & 1.0 & 0.35 \\
$\mathrm{~S}$ & 0.01 & 0.03 & 0.01 \\
$\mathrm{P}$ & 0.01 & 0.03 & 0.015 \\
$\mathrm{Si}$ & 0.35 & 0.5 & 0.20 \\
$\mathrm{Al}$ & $0.4-0.6$ & $0.1-0.5$ & 0.35 \\
$\mathrm{Nb}+\mathrm{Ta}$ & $4.75-5.50$ & 0.5 & $2.7-4.0$ \\
$\mathrm{Co}$ & 1.0 & -- & - \\
$\mathrm{Ti}$ & $0.8-1.15$ & $1.9-2.4$ & $1.0-1.7$ \\
\hline
\end{tabular}

\section{Heat Treatment}

The standard heat treatment for 718 is carried out for aerospace applications to achieve better creep resistance and rupture life and for best transverse ductility. This heat treatment produces 150-ksi minimum yield strength, and, based on past experience and laboratory tests, this was not considered optimum for downhole applications.

An annealing temperature of 1850 to $1925^{\circ} \mathrm{F}$ was chosen, since a low annealing temperature close to 1700 to $1750^{\circ} \mathrm{F}$ was not sufficient to homogenize the microstructure from prior processing operations. The higher temperature provided both better homogeneity and dissolved precipitation of deleterious phases and duplex grain structure. $1925^{\circ} \mathrm{F}$ was chosen as maximum annealing temperature to avoid large grain growth. For specification purposes, a temperature range of 1850 to $1900^{\circ} \mathrm{F}$ was selected.

As shown in Figure 3, 120-ksi yield strength (YS) can be achieved by under-aging at approximately $1200^{\circ} \mathrm{F}$ or by over-aging at $1450^{\circ} \mathrm{F}$. The oil and gas industry is governed by NACE standard MR-0175 for sour service application; thus, the restriction on maximum hardness for sour service was 35 HRC. A $120 \mathrm{ksi}$ YS was achievable with 35-HRC max by under-aging, but it was difficult to achieve on a consistent basis. An additional heat treatment study was completed to optimize mechanical properties and cracking resistance. It was found that, by over-aging at $1450^{\circ} \mathrm{F}$, a 120 -ksi YS was obtained on a consistent basis with a hardness of $40 \mathrm{HRC}$. The NACE standard MR-0175 limit was balloted after several industry laboratories verified $\mathrm{SCC}$ resistance at the higher hardness level (40 HRC). 


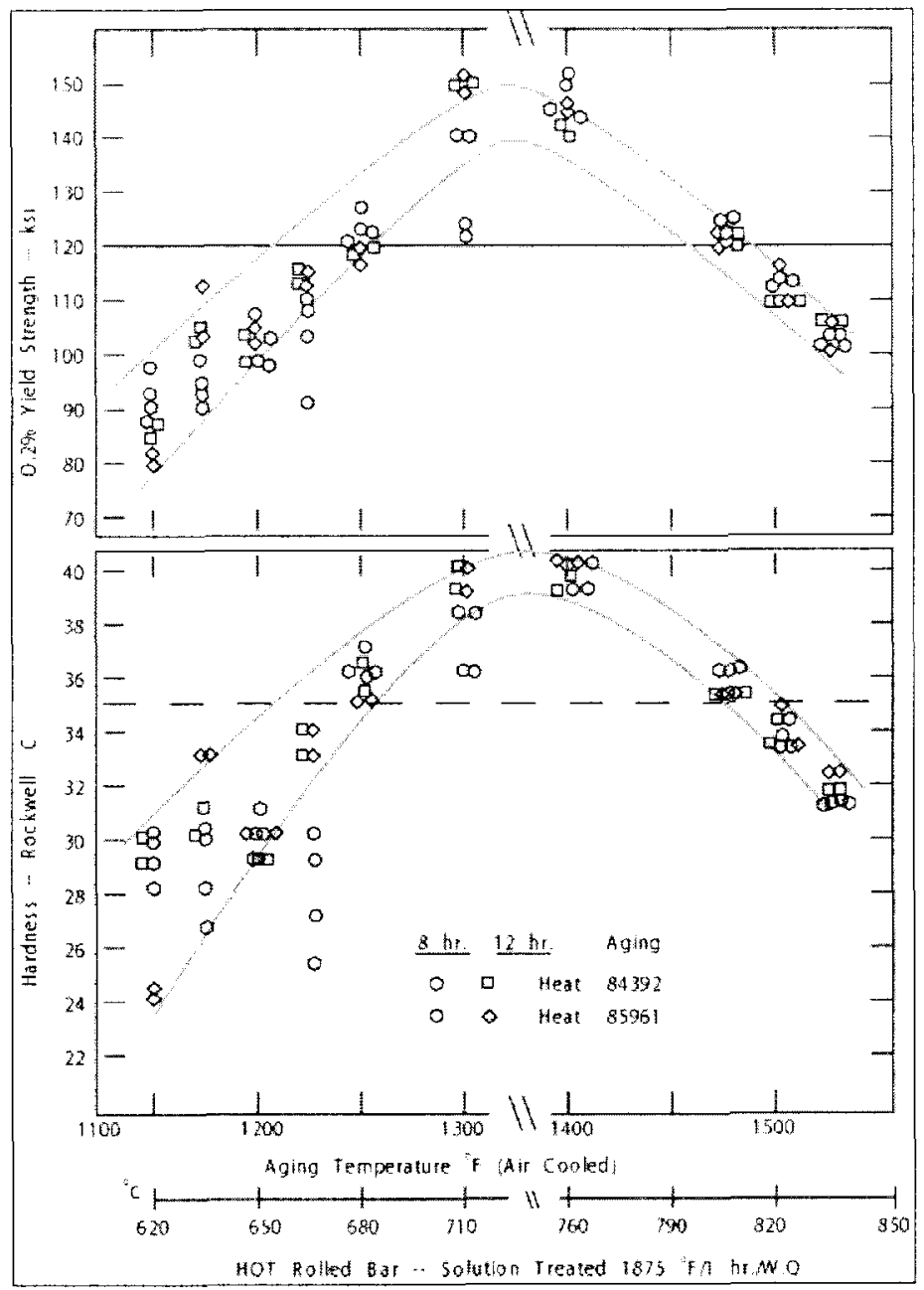

Figure 3: Effect of aging temperature and time on hardness and yield strength

\section{Corrosion Resistance}

The latest applications of Alloy 718 in downhole equipment are found in wells with extremely corrosive environments. The general corrosion resistance of 718 in several sour gas environments is shown in Table II. Minimal corrosion rates are observed in hot sour brines up to temperatures of $400^{\circ} \mathrm{F}$. Localized corrosion and SCC becomes a concern in the presence of sulfur. The materials were tested for 14 day in $15 \% \mathrm{NaCl} /$ distilled water with total gas pressure of 1000 psi with 500 psi $\mathrm{CO}_{2}$ plus $\mathrm{N}_{2}$ and varying amounts of $\mathrm{H}_{2} \mathrm{~S}$ (Ref. 1)

Table II General Corrosion Resistance of 718 and 925 Alloys in Sour Environments

\begin{tabular}{llll}
\hline Alloy & $\mathrm{H}_{2} \mathrm{~S}$ Pressure & Corrosion Rate $-300^{\circ} \mathrm{F}$ & Corrosion Rate- $400^{\circ} \mathrm{F}$ \\
\hline 718 & $10 \mathrm{psi}$ & $3.0 \mathrm{mpy}(0.076 \mathrm{~mm} / \mathrm{y})$ & $0.3 \mathrm{mpy}(0.008 \mathrm{~mm} / \mathrm{y})$ \\
& $50 \mathrm{psi}$ & $0.7 \mathrm{mpy}(0.018 \mathrm{~mm} / \mathrm{y})$ & $2.3 \mathrm{mpy}(0.058 \mathrm{~mm} / \mathrm{y})$ \\
925 & $100 \mathrm{ps}$ & $0.1 \mathrm{mpy}(0.003 \mathrm{~mm} / \mathrm{y})$ & $1.2 \mathrm{mpy}(0.030 \mathrm{~mm} / \mathrm{y})$ \\
& $0 \mathrm{psi}$ & $0.1 \mathrm{mpy}(0.003 \mathrm{~mm} / \mathrm{y})$ & $0.1 \mathrm{mpy}(0.003 \mathrm{~mm} / \mathrm{y})$ \\
& $50 \mathrm{psi}$ & $0.4 \mathrm{mpy}(0.010 \mathrm{~mm} / \mathrm{y})$ & $0.5 \mathrm{mpy}(0.058 \mathrm{~mm} / \mathrm{y})$ \\
& $100 \mathrm{psi}$ & $0.1 \mathrm{mpy}(0.003 \mathrm{~mm} / \mathrm{y})$ & $0.4 \mathrm{mpy}(0.010 \mathrm{~mm} / \mathrm{y})$
\end{tabular}


The general corrosion and pitting resistance are sensitive to heat treatment. The reduction in corrosion resistance can be attributed to the precipitation of carbides and segregation of alloying elements during heat treatment. The slight loss of resistance observed is due to chromium depletion in localized regions due to heat treatment. For downhole completion equipment applications, the heat treatment has been standardized to provide optimization for strength, toughness and corrosion resistance. The heat treatment for most applications involves a solution anneal at $1850^{\circ} \mathrm{F}-1900^{\circ} \mathrm{F}$ for a 1 hour minimum to a 2 hour maximum. The aging treatment is carried out at $1450+/-25^{\circ} \mathrm{F}$ for a minimum of 6 to 8 hours.

\section{Acidizing Resistance}

The resistance of 718 to common acidizing systems (i.e., $10 \% \mathrm{HCl}$ ) is comparable to other CRAs with which they would be commonly used. These are 825, SM2550, or G3. Generally, exposure to concentrated hot acid is limited to less than a day; however, completion components can be exposed to low $\mathrm{pH}$ in partially spent acid environments for several days. Alloy 718 corrosion rates are on the order of 4 mils per day in boiling $10 \% \mathrm{HCl}$.

\section{Hydrogen Embrittlement}

Concern regarding $\mathrm{HE}$ in the aerospace industry where 718 is used at very high-strength levels (170ksi) prompted investigations in the oil industry. Despite proven HE susceptibility at highstrength levels, various oil industry laboratories have shown that 718 , limited to a hardness of 40 HRC, is not susceptible to delayed failure in NACE TM-0177 solutions even when coupled to carbon steel. High-temperature aging treatments are required for improved resistance to environmental embrittlement. Thus, by limiting strength and hardness of 718 , many successful oilfield applications exist.

\section{Stress Corrosion Cracking Resistance}

The utility of alloy 718 is derived from adequate resistance to chloride stress corrosion cracking in the presence of brines and significant quantities of carbon dioxide and $\mathrm{H}_{2} \mathrm{~S}$. However, alloy 718 is susceptible to high-temperature chloride stress corrosion cracking when elemental sulfur is present in high partial pressure $\mathrm{H}_{2} \mathrm{~S}$ environments. Maximum temperatures are limited to 275 to $300^{\circ} \mathrm{F}$ for these applications. For more demanding applications, where stress corrosion cracking resistance in the presence of high $\mathrm{H}_{2} \mathrm{~S}$ and temperatures of $450^{\circ} \mathrm{F}$ is required, alloy 725 can be considered.

\section{Applications for Completion Equipment}

Alloy 718, Incoloyß 925 and 625 modified alloys are commonly used in oil and gas industry for various applications. These severe environment wells have significant concentrations of $\mathrm{H}_{2} \mathrm{~S}$, $\mathrm{CO}_{2}$, chlorides and high bottom hole temperatures. The largest use is for downhole tools such as subsurface safety valves, packers, flow control devices and other tools. These alloys are also used for wellhead components and valve bodies. Cast 718 is also used for some of the complex shapes.

Compared to other stainless steels used, these alloys also experience a relatively small drop in strength at operating temperatures as shown in Figure 4. These alloys are available in various sizes of bar products to cover the equipment range. Their ability to be forged and welded makes them attractive for many of these tools. Alloy 718 has been successfully used in fabrication of side pocket mandrels used for artificial lifting of oil by injection gas. These mandrels are fully annealed and aged after welding to achieve higher strength and restore corrosion resistance. 


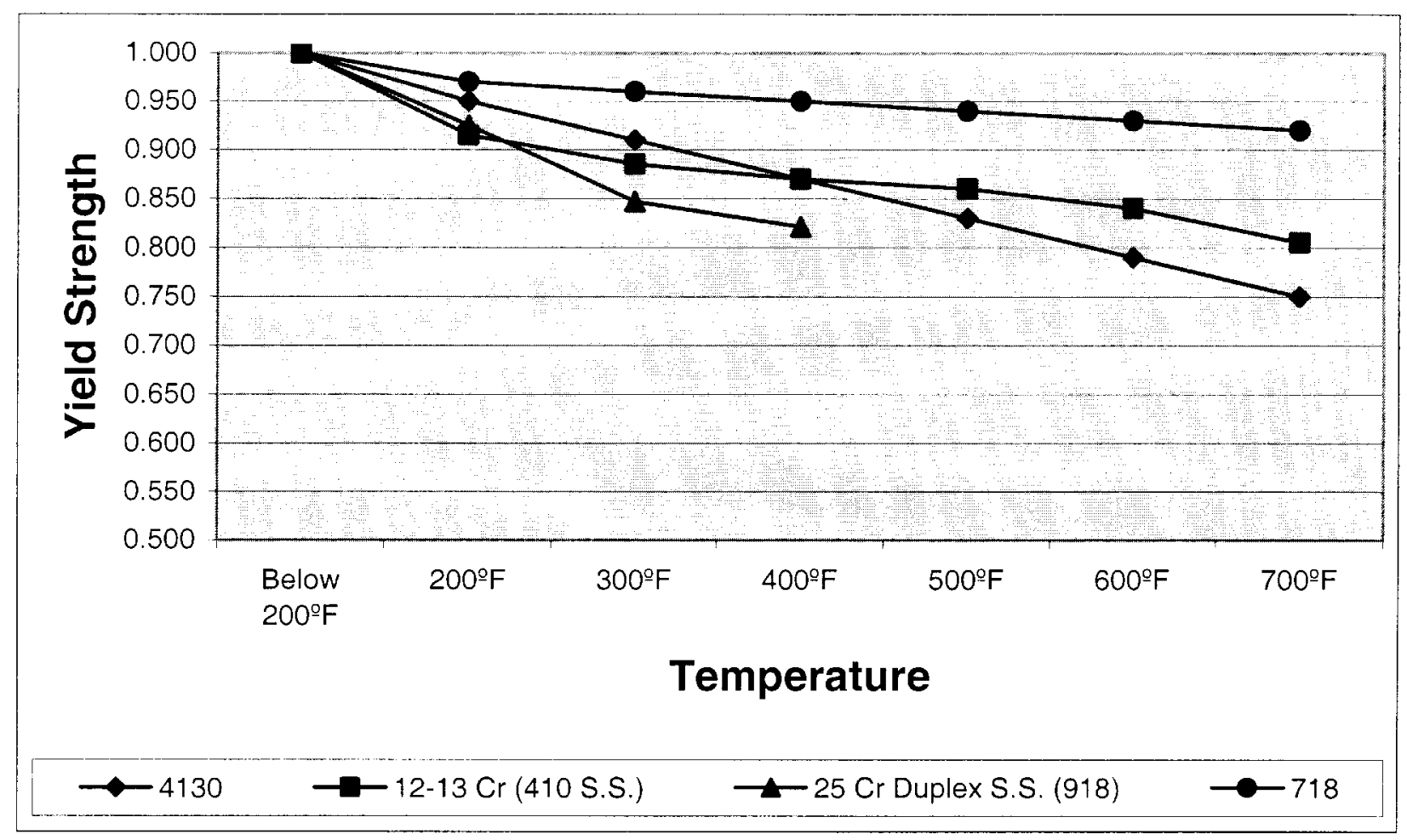

Figure 4: Drop in Yield Strength at Elevated Temperatures of Various Materials

\section{Drilling Industry Applications}

The widespread application of directional drilling has also led to some interesting applications of 718. In order to steer a well bore in the desired direction, it is necessary to make repeated measurements of the borehole direction. This is accomplished by measurement while drilling (MWD) tools that are placed behind the drill bit in a bottom hole assembly. One of the key measurements is the orientation of the MWD tools with respect to the earth's magnetic field. It is obvious that this requires that all the materials in the region of the sensor be nonmagnetic.

The more difficult restrictions on available materials come from the combination of strength and size required. The measurement tools must be built to fit within the lower part of the drill string while still allowing drilling mud to be pumped through to lubricate and cool the drill bit. Drill cuttings must also be conveyed to the surface. The mud, which is an abrasive slurry, is typically at a pressure of 10,000 psi to 25,000 psi. The essential components require nonmagnetic materials ranging in diameters from 3 to 6 in. with 120- to 150-ksi yield strength. The list of materials that meet the strength and magnetic criteria alone is quite short. Most of these materials, such as austenitic stainless steels, require either significant cold work (i.e., 310 SS) or a combination of cold work and aging (i.e., cobalt-based alloy R30300) to achieve the required strength. It is very difficult to achieve the required levels of cold work in large sections, so a heat-treatable material with deep hardenability is required. This limits the choices rather severely. For nonmagnetic materials with adequate corrosion resistance, only beryllium copper, a few titanium alloys and 718 were commercially available in the 1980 s to meet the strength requirement. All of these materials have been used in MWD applications. However, only 718 met the hardenability requirements for large diameters. Yield strengths of $150 \mathrm{ksi}$ can be achieved with beryllium copper up to a 2 -in. diameter and with Ti6Al4V up to a 3 -in. diameter.

The drilling environment is demanding in other respects as well. Drilling mud can be quite corrosive. Many water-based drilling muds have very high chloride contents (saturation with salt is not uncommon); they are rarely oxygen free; and they can have a $\mathrm{pH}$ level ranging from 5 
to 13. In difficult drilling conditions, hydrochloric acid is sometimes pumped through the drill string to free it when it is stuck in limestone formations, which reduces the $\mathrm{pH}$ down to zero.

Elemental sulfur can also accumulate in the mud. Hydrogen sulfide is normally not a significant concern for MWD components inside the drill collar, because any $\mathrm{H}_{2} \mathrm{~S}$ produced during drilling is either removed or neutralized at the surface before the mud is re-circulated down the drill string. Most nickel alloys, as well as some stainless steels and copper alloys, can withstand these demanding conditions. 718 exhibits very little corrosion in this environment, and it does not suffer from stress-corrosion cracking, even at the highest strength levels normally used.

\section{Machinability Issues}

718 is the natural initial design choice for MWD tools where nonmagnetic properties are required. In practice, its use is limited by two factors: material cost and machinability. 718 is much less machinable than austenitic stainless steels. Using carbide tooling, speeds and feeds are 2 to 4 times less than for the stainless steels. This is compounded by very heavy tool wear, especially on milling cutters and taps. This has caused total machining costs to more than double the costs of cold-worked stainless steels of similar strength. Oxide-ceramic tooling, which allows increased cutting speeds, has recently been introduced, and this has significantly reduced machining costs when it can be used. Machining costs are also reduced by using the oilfield heat treatment, which meets the NACE requirement of 40-HRC maximum with 120-ksi yield strength, rather than the AMS 5663 heat treatment with 150-ksi yield strength.

\section{Fatigue Life and Grain Size}

The significant advantages of 718 that have been found include slightly higher fatigue strength and freedom from corrosion. Fatigue strength in 718 is strongly affected by grain size, and, with typical grain sizes of ASTM 3 to 5, the endurance limit is found to be greater than $60 \mathrm{ksi}$, which is a little above the Cr-Mn stainless steels normally used. Recent developments in these stainless steels have increased their fatigue limit to $65 \mathrm{ksi}$. To exceed this limit in 718 requires significant grain refinement. Schlumberger has recently started procuring material with very fine grain, typically ASTM 8, in order to get a higher endurance limit of 65 to $70 \mathrm{ksi}$.

This is made possible by dropping the creep strength requirements of AMS 5663 which effectively requires coarse grains stabilized by delta phase, $\mathrm{Ni}_{3} \mathrm{Cb}$. By minimizing the formation of delta phase, and maintaining it as a fine dispersion, a fine grain size can be achieved in hot work and maintained through heat treatment. While it might be expected that the resulting material would also have improved toughness, all that can be confirmed so far is that Charpy impact values are comparable to those for AMS 5663 material.

\section{Alloy 725 and 925}

Alloy 725 is a Ni-Cr-Mo-Nb alloy that is highly corrosion resistant and age-hardenable. It fills the need for greater environmental cracking resistance at high temperatures in deep, extremely hostile, oil and gas production environments. It offers better cracking resistance at elevated temperatures in higher levels of $\mathrm{H}_{2} \mathrm{~S}$ due to the higher content of molybdenum. The use of these alloys are required and are justified in gas wells with partial pressures of $\mathrm{H}_{2} \mathrm{~S}$ in excess of 200 psi, high $\mathrm{CO}_{2}$ and temperatures around $400^{\circ} \mathrm{F}$. Alloy 725 is used with 120 -ksi minimum yield strength with 40-HRC maximum hardness. However, recent work, performed by Special Metals Corporation, shows it can be used with 140-ksi minimum yield strength and 42-HRC maximum hardness. The higher strength offers the opportunity to optimize complex geometries for highly stressed components. Applications for 725 in the oil and gas industry include subsurface safety valves, hangers, landing nipples and side pocket mandrels. 
Alloy 925 is a slightly less expensive alloy with a lower Ni and Mo content compared to 725 . The compositions for these alloys can be found in Table I. Alloy 925 is strengthened by precipitation of gamma prime $\left[\mathrm{Ni}_{3}(\mathrm{Ti}, \mathrm{Al})\right]$ and 725 by gamma double prime $\left[\mathrm{Ni}_{3}(\mathrm{Nb}, \mathrm{Ti}, \mathrm{Al})\right]$ phases. Minimum yield strengths of $105 \mathrm{ksi}$ and $120 \mathrm{ksi}$ can be achieved by anneal and age heat treatments. Heat treatments have been optimized to obtain the best combination of strength, toughness and corrosion resistance.

Alloy 925 has resistance to pitting and $\mathrm{SCC}$ in environments containing $\mathrm{Cl}, \mathrm{H}_{2} \mathrm{~S}$ at temperatures from $300-325^{\circ} \mathrm{F}$. In contrast, 725 is resistant to similar environments up to $450-500^{\circ} \mathrm{F}$. Both alloys are fully resistant to low-temperature sulfide stress cracking in the NACE TM-0177 test.

Both alloys are weldable. Welding with alloy 725 provides a high-strength alternative to alloy 625 welding products. Gas-tungsten-arc welding and gas-metal-arc-welding are the preferred methods for welding alloy 725. The ability to weld these alloys allows fabrication of complicated parts for downhole equipment in these materials. Examples are chemical injection valves, side pocket mandrels and gauge mandrels.

\section{References}

1. E.L Hibner and R.H. Moeller, Corrosion Resistant Alloys UNS N09925 and N07725 for Oilfield Applications, Offshore Technology Conference Paper No. 7206, 1993

\section{Bibliography}

2. Corrosion Resistant Alloys in Oil and Gas Production, Vol. II, Edited by J. Kolts and S.W. Ciaraldi. (NACE Publications). Compilation Published 1996.

Note: Monel and Incoloy are registered trademarks of the Special Metals Corporation. 